\title{
Generalized Familial Crown Resorptions in Unerupted Teeth
}

Ozkan Miloglu

Mustafa Goregen ${ }^{b}$

Hayati Murat Akgulc

Abubekir Harorlid

\section{ABSTRACT}

This paper reports the case of 2 sisters with generalized familial crown resorptions, including co-occurrence of familial dental abnormalities of severe crown resorption, failure of eruption, and congenitally missing teeth, which have not been described earlier in the literature. (Eur J Dent 2011;5:206-209)

Key words: Crown resorption; Unerupted teeth; Dental anomalies; Amelogenesis imperfecta; Regional odontodysplasia.

\section{INTRODUCTION}

Coronal resorption of teeth is a possible complication of chronic impaction. A tooth that remains embedded for a long period is prone to resorption. ${ }^{1}$ Histologically, the enamel of the crown is frequently resorbed rather than the root surface or the cementoenamel junction. Destroyed pericoronal epithelium and replacement of dental

a Assistant Professor, Department of Oral Diagnosis and Radiology, Faculty of Dentistry, Ataturk University, Erzurum, Turkey.

b Postgraduate Doctor, Department of Oral Diagnosis and Radiology, Faculty of Dentistry, Ataturk University, Erzurum, Turkey.

c Associate Professor, Department of Oral Diagnosis and Radiology, Faculty of Dentistry, Ataturk University, Erzurum, Turkey.

d Professor, Department of Oral Diagnosis and Radiology, Faculty of Dentistry, Ataturk University, Erzurum, Turkey.

- Corresponding author: Ozkan Miloglu Department of Oral Diagnosis and Radiology, Faculty of Dentistry, Ataturk University, Erzurum, 25240, Turkey. Phone: +90 4422311778 Fax: +90 4422360945 E-mail: omilogluahotmail.com enamel by bone are typical histological findings in such cases. ${ }^{2}$ Seddon et al $^{1}$ stated that coronal resorption of impacted canines is preceded by the degeneration of the enamel epithelium, which allows direct contact of the connective tissues with enamel. Gradually, the enamel is replaced by bone in an irregular manner, and this process sometimes spans a considerable period of time.

Four theories have been proposed to explain coronal resorptions: ${ }^{3}$

1. Apical inflammation in a primary precursor, which affects the permanent successor. However, this theory does not explain the coronal resorption in molars.

2. Dental caries, though it has still not been proven that caries hampers tooth eruption.

3. Developmental abnormality manifesting as enamel or dentin hypoplasia or as an inclusion of uncalcified enamel matrix, as described by Walton. ${ }^{4}$

4. Internal/external resorption. Internal resorption is initiated within the pulp cavity, whereas 
external resorption is initiated in the periodontium and affects the external or lateral surfaces of a tooth.

The cases discussed here show common familial crown resorptions, abnormalities in tooth eruption, and congenital absence of teeth in 2 sisters.

\section{CASE REPORTS}

Case I

A 35-year-old woman was referred to the Department of Oral Diagnosis and Oral Radiology complaining of dental pain and swelling. Her medical history was unremarkable, and her hair, skin, and nails appeared normal. She had had an eventful pregnancy and postnatal period. Intraoral examination showed that she had no teeth in the mandible because of which she used a complete denture, whereas she required a fixed partial denture among the first molars in the maxilla. There was no fistula or enlargement of the gingival tissues in the concerned area.

Periapical radiography showed an apically radiolucent lesion of the upper right lateral incisor (Figure 1). Additionally, we noticed an unerupted canine with a resorbed crown in the periapical area. By panoramic radiography, we observed that 8 teeth in the maxilla and 12 teeth in the mandible had failed to erupt. None of the unerupted teeth had a crown (Figure 2). The resorption of the unerupted teeth involved the enamel, dentin, and pulp chamber. In addition, 3 teeth in maxilla and 4 teeth in mandible were congenitally missing (Table 1).

\section{Familial history}

On the basis of our observations, the hereditary characteristics of this patient were investigated by involving her family members. Her parents had passed away. According to the patient, her mother had a similar condition, but her father did not. She had 2 sisters and 1 brother. We noted similar findings in one of her sisters. No dental pathology was found in the sisters' children or husbands (Figure 3).

\section{Case II}

The patient's sister is a 32-year-old woman with an unremarkable medical history and normal hair, skin, and nails. She had had an uneventful pregnancy and postnatal period. Intraoral exami- nation revealed that the patient had a fixed partial denture in both the jaws and no pathologies in the soft tissues. Panoramic x-ray analysis showed that 6 teeth in both jaws had failed to erupt (Figure 3). None of these teeth had crowns. The resorptions of the unerupted teeth involved the enamel, dentin, and pulp chamber (Figure 4). In addition, 4 teeth in the maxilla and 3 teeth in the mandible were congenitally absent (Table 1). Any tooth that is radiographically absent without any history of prior extraction, is considered to be congenitally absent.

\section{DISCUSSION}

This article presents the case of 2 sisters with similar familial dental abnormalities manifesting as severe crown resorption, failed tooth eruption, and congenitally missing teeth. This is the first report to present such a familial dental abnormality. Previous reports showed that the pre-eruptive crown resorptions affected the maxillar canines, mandibular molars, premolars, and canines, ${ }^{1,3,5,6}$ and the defects were usually minor and occurred in not more than 2 teeth per patient. ${ }^{6,7}$ Peters et $\mathrm{al}^{8}$ reported that failure of eruption and crown resorption were only limited to the second and third molars in all the quadrants.

Dental abnormalities such as taurodontism, congenitally missing teeth, failure of eruption, root and crown resorption, root malformation, and hypercementosis are reported to be related to amelogenesis imperfecta (Al).9-12 Korbmacher et $\mathrm{al}^{13}$ reported the case of a patient with progressive pre-eruptive crown resorption in autosomal recessive generalized hypoplastic Al. Similarly, Wright ${ }^{14}$ reported active resorption of the crowns of unerupted teeth in 2 siblings affected by autosomal recessive Al. The findings of the present cases (crown resorption, failure of eruption, and congenitally missing teeth) may be reminiscent of Al. However, since all the teeth were artificially restored with fixed partial dentures and the patients did not permit the extraction of any unerupted tooth for histological examination, we could not clarify whether these cases were related to Al.

Regional odontodysplasia (RO) affects both the mesodermal and ectodermal dental components and delays teeth eruption; in most cases, teeth fail to erupt. ${ }^{15}$ Mock et al $^{16}$ reported RO anomaly in 2 siblings, where both the mesodermal and ec- 
todermal components of the entire dentition were affected. These cases are identical to ours, except that in our cases, the dentinal involvement was more extensive. However, some of the features of RO were absent in both the current cases, including radiographic evidence of "ghost teeth." Additionally, histological evidence was lacking.

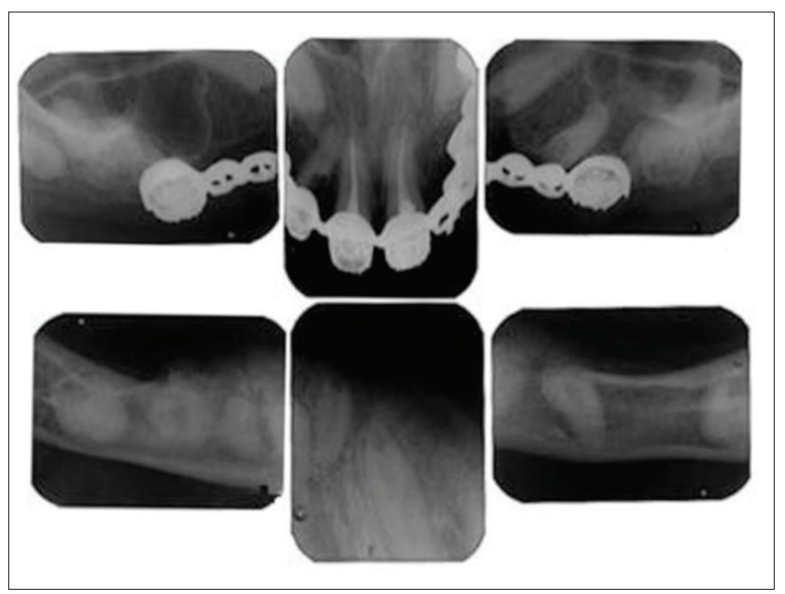

Figure 1. Periapical radiographs of case I.

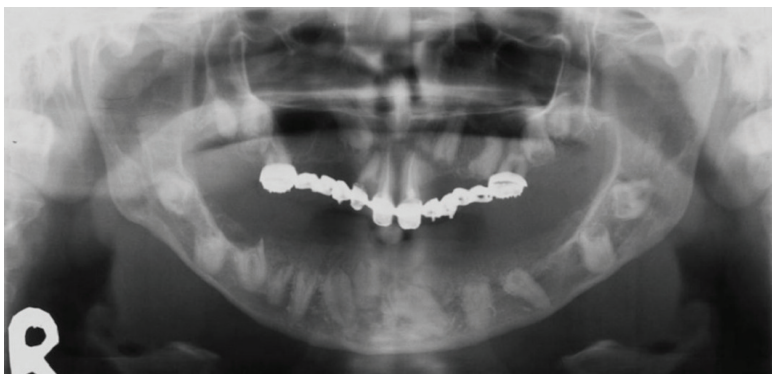

Figure 2. Panoramic radiograph of case I showing severe coronal resorptions in the unerupted teeth on both jaws.

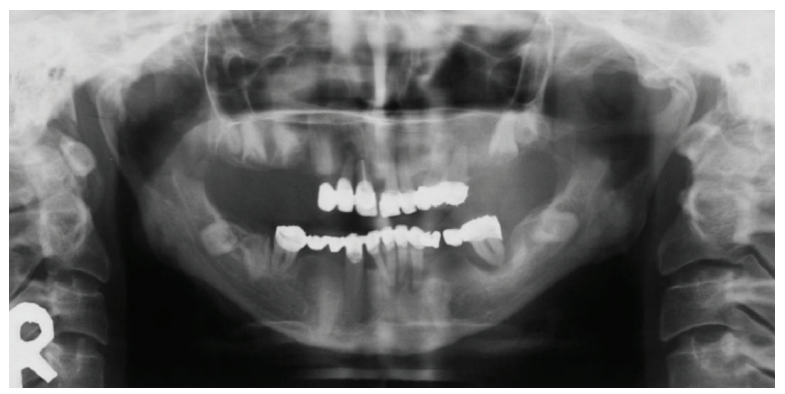

Figure 4. Panoramic radiograph of case II showing periapical radiolucent areas in erupted teeth and severe coronal resorptions in the unerupted teeth on both jaws.
In our cases, the abnormality may be hereditary. We were able to examine 3 generations in this family. The disorder was observed in 2 sisters. One patient stated that her mother was affected by a similar condition, while no such abnormality was seen in her father. The number of individuals according to familial pedigree was considerably low,

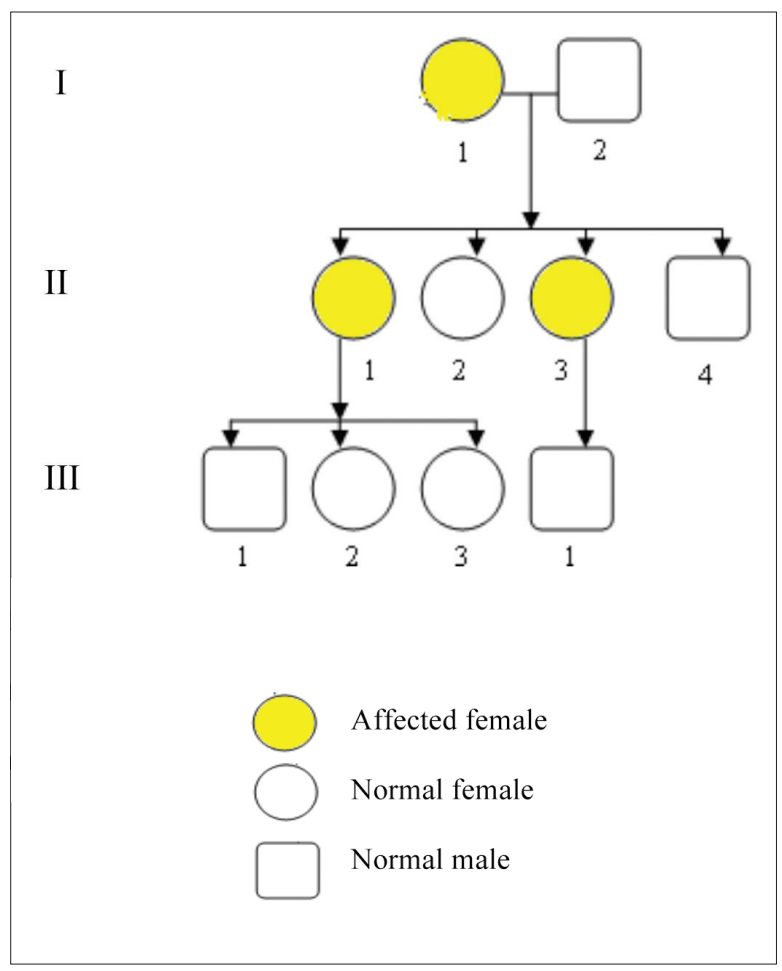

Figure 3. Family heredogram.

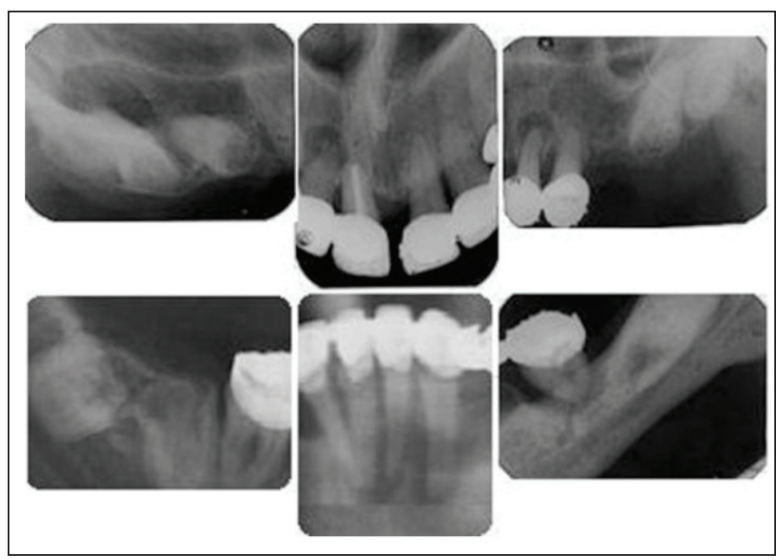

Figure 5. Periapical radiographs of case II showing periapical radiolucent areas in erupted teeth and severe coronal resorptions that involved enamel, dentin and pulpal chamber in the unerupted teeth.

Table 1. Findings of clinical and radiological examination in both cases

\begin{tabular}{lcc}
\hline & Case I & Case II \\
\hline \multirow{2}{*}{ Unerupted teeth } & $13,17,18,22,23,25,27,28,33,34$, & $13,15,17,18,27,28$, \\
& $35,37,38,41,43,44,45,46,47,48$ & $34,38,42,44,47,48$ \\
Existing teeth & $11,12,16,21,26$ & $11,12,21,22,24,25$, \\
Missing teeth & $14,15,24,31,32,36,42$ & $31,32,33,36,41,43,46$ \\
\hline
\end{tabular}


and thus, a valid genetic evaluation was not possible. Under these circumstances, we can suggest that the present cases may be either autosomal dominant or x-linked dominant.

We could not detect any pathologic condition or apical lesion in either case in this study. Therefore, patients who may have undergone dental surgery is not implemented the request. However, some erupted teeth have been detected in patients with either apical lesions or advanced periodontal problems. Therefore, both the patients received surgical intervention.

\section{REFERENCES}

1. Seddon RP, Orth D, Smith PB. Early arrested development and coronal resorption of an impacted maxillary canine: report of case. ASDC J Dent Child 1996;63:208-212.

2. Azaz B, Shteyer A. Resorption of the crown in impacted maxillary canine. A clinical, radiographic and histologic study. Int J Oral Surg 1978;7:167-171.

3. O'Neal KM, Gound TG, Cohen DM. Preeruptive idiopathic coronal resorption: A case report. J Endod 1997;23:58-59.

4. Walton JL. Dentin radiolucencies in unerupted teeth: report of two cases. ASDC J Dent Child 1980;47:183-186.

5. Seow WK. Multiple preeruptive intracoronal radiolucent lesions in the permanent dentition: case report. Pediatr Dent 1998;20:195-198.

6. Dowling PA, Fleming P, Corcoran F. A case report of preeruptive coronal resorption in a mandibular canine. Dent Update 1999:26:444-445.

7. Nik NN, Abul Rahman R. Pre-eruptive intracoronal dentin defects of permanent teeth. J Clin Pediatr Dent 2003;27:371 375.

8. Peters E, Cohen M, Altini M. Rough hypoplastic amelogenesis imperfecta with follicular hyperplasia. Oral Surg Oral Med Oral Pathol 1992;74:87-92.

9. Collins MA, Mauriello SM, Tyndall DA, Wright JT. Dental anomalies associated with amelogenesis imperfecta: a radiographic assessment. Oral Surg Oral Med Oral Pathol Oral Radiol Endod 1999;88:358-364.

10. Aldred MJ, Savarirayan R, Lamande SR, Crawford PJ. Clinical and radiographic features of a family with autosomal dominant amelogenesis imperfecta with taurodontism. Oral Dis 2002;8:62-68.

11. Price JA, Wright JT, Walker SJ, Aldred MJ, Hart TC. Trichodento-osseous syndrome and amelogenesis imperfecta with taurodontism are genetically distinct conditions. Clin Genet 1999;56:25-40.
12. Atasu M, Biren S, Mumcu G. Hypocalcification type amelogenesis imperfecta in permanent dentition in association with heavily worn primary teeth, gingival hyperplasia, hypodontia and impacted teeth. J Clin Pediatr Dent 1999;23:117-121.

13. Korbmacher HM, Lemke R, Kahl-Nieke B. Progressive pre-eruptive crown resorption in autosomal recessive generalized hypoplastic amelogenesis imperfecta. Oral Surg Oral Med Oral Pathol Oral Radiol Endod 2007;104:540544.

14. Wright JT. Analysis of kindred with amelogenesis imperfecta. J Oral Pathol 1985;14:366-374.

15. Neville BW, Damm DD, Allen CM, Bouquot JE. Oral and Maxillofacial Pathology. $1^{\text {st }}$ ed. Philadelphia: WB Saunders Company, 1995;79-84.

16. Mock D, Aidelbaum MR, Chapnick P. Familial amelodentinal dysplasia. Oral Surg Oral Med Oral Pathol 1986;61:485491 